Orthopaedics

\section{A painful and deformed wrist}

\section{K S David-West, E R Gardner}

$\mathrm{A}$ 54 year old man fell off stairs with his left wrist in the flexed position. He was seen in the accident and emergency department within one hour of the injury, with a painful and deformed wrist with dorsoulna displacement. There was a tingling sensation over the little finger but no objective sensory loss and good perfusion of the digits. The skin over the wrist was intact and there were no other injuries. The forearm was splinted before radiography of the wrist was performed (see fig l).

\section{QUESTIONS}

(1) What does the radiograph show?

(2) What are the possible complications associated with this injury?

(3) How will you treat this injury?

Postgrad Med J 2002;78:183

Authors' affiliations

K S David-West, E R Gardner, Orthopaedic Department, Victoria Infirmary, Glasgow G42 9TY, UK
Correspondence to: Mr Gardner

Submitted 27 February 2001

Accepted 15 May 2001

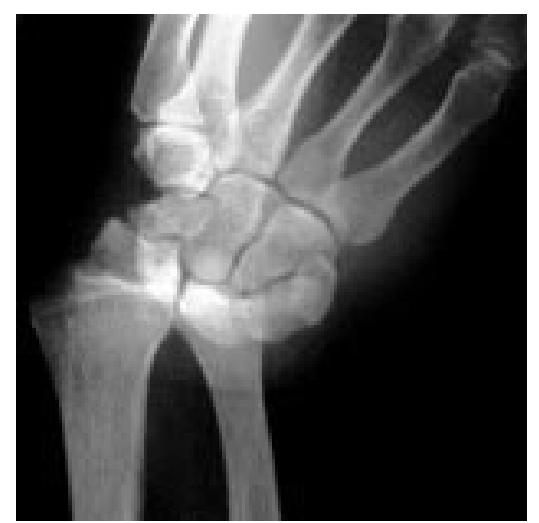

Figure 1 Radiograph of patient's wrist.

(2) What possible diagnoses are compatible with the patient's clinical presentation?

\title{
Massive haemoptysis in a young woman
}

\section{O Dikensoy, N G Bayram, A Filiz}

\section{Answers on $p 187$.}

$\Lambda^{2}$ 24 year old woman was admitted to our hospital for a massive haemoptysis with abrupt onset. The average amount of blood expectorated was $200-250 \mathrm{ml}$ in 24 hours. She was a nonsmoking housewife living in a rural area. Her medical history was unremarkable except for the presence of recurrent oral and genital ulcers for three years, and skin lesions consistent with erythema nodosum had occurred one year previously. Her vital signs on admission were as follows: temperature $37^{\circ} \mathrm{C}$, blood pressure $110 / 70 \mathrm{~mm} \mathrm{Hg}$, pulse rate 120 beats/min, and respiratory rate 28 breaths/min. Physical examination of the chest was normal. Admission laboratory values were as follows: leucocyte count $9.3 \times 10^{9} /$, haemoglobin concentration $120 \mathrm{~g} / \mathrm{l}$, packed cell volume 0.34 , platelet count $42 \times 10^{9} / 1$, erythrocyte sedimentation rate $44 \mathrm{~mm} /$ hour, alanine aminotransferase $48 \mathrm{IU} / \mathrm{l}$ (normal range 0-40 IU/l), aspartate aminotransferase 34 IU/l (normal range 0-40 IU/l), lactate dehydrogenase 657 IU/l (normal range 240$480 \mathrm{IU} / \mathrm{l})$. Serum electrolytes, renal function, urinalysis, prothrombin time, and activated partial thromboplastin time were all in the normal ranges. Her chest radiograph showed two rounded opacities bilaterally with fine margins with an average size of $3 \times 5 \mathrm{~cm}$ (fig 1). Purified protein derivative by Mantoux testing was $17 \mathrm{~mm}$.

\section{QUESTIONS}

(1) What investigation would you perform next?

Postgrad Med J 2002;78: 183
(3) What is the most likely diagnosis?

(4) What investigations would you perform to confirm your diagnosis?

(5) How would you manage this patient?

\section{Authors' affiliations}

O Dikensoy, N G Bayram, A Filiz, Gaziantep University, School of Medicine, Department of Pulmonary Diseases, 27070, Gaziantep, Turkey

Correspondence to: Dr Dikensoy; dikensoy@yahoo.com

Submitted 1 May 2001

Accepted 7 August 2001

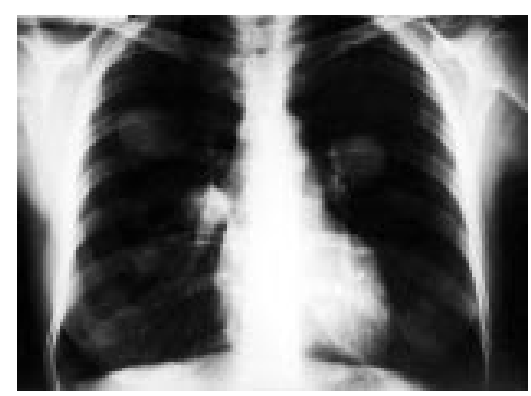

Figure 1 Chest radiograph revealing multiple, bilateral opacities. 